\title{
Haematology and plasma chemistry of the red top ice blue mbuna cichlid (Metriaclima greshakei)
}

\author{
Donna L. Snellgrove* and Lucille G. Alexander \\ WALTHAM Centre for Pet Nutrition, Freeby Lane, Waltham-on-the-Wolds, Melton Mowbray, Leicestershire LE14 4RT, UK
}

(Received 15 October 2010 - Revised 24 February 2011 - Accepted 17 March 2011)

\begin{abstract}
Clinical haematology and blood plasma chemistry can be used as a valuable tool to provide substantial diagnostic information for fish. A wide range of parameters can be used to assess nutritional status, digestive function, disease identification, routine metabolic levels, general physiological status and even the assessment and management of wild fish populations. However to evaluate such data accurately, baseline reference intervals for each measurable parameter must be established for the species of fish in question. Baseline data for ornamental fish species are limited, as research is more commonly conducted using commercially cultured fish. Blood samples were collected from sixteen red top ice blue cichlids (Metriaclima greshakei), an ornamental freshwater fish, to describe a range of haematology and plasma chemistry parameters. Since this cichlid is fairly large in comparison with most tropical ornamental fish, two independent blood samples were taken to assess a large range of parameters. No significant differences were noted between sample periods for any parameter. Values obtained for a large number of parameters were similar to those established for other closely related fish species such as tilapia (Oreochromis spp.). In addition to reporting the first set of blood values for $M$. Greshakei, to our knowledge, this study highlights the possibility of using previously established data for cultured cichlid species in studies with ornamental cichlid fish.
\end{abstract}

Key words: Cichlid: Haematology: Plasma chemistry: Metriaclima greshakei: Ornamental fish

Haematology and blood chemistry parameters have generally been studied in fish species commonly used in research or cultured as a food source. For species such as salmon (Salmo salar), rainbow trout (Oncorbynchus mykiss), carp (Cyprinus carpio), catfish (Clarias gariepinus) and tilapia (Oreochromis Hybrid), reference ranges have been established ${ }^{(1-6)}$ and are used to evaluate clinical status. Haematology data for ornamental fish species are limited and often restricted to common cyprinid species such as the goldfish and koi carp ${ }^{(7,8)}$. Parameters for a couple of large aquarium species, such as the red pacu (Piaractus brachypomus) and the Acadian redfish (Sebastes fasciatus), have now been documented ${ }^{(9,10)}$. There is a vast number of aquarium-held ornamental fish, and while these two fish may provide representative baseline data for both Characiformes and Scorpaeniformes, data are still lacking for other major groups of ornamental fish.

The red top ice blue cichlid (Metriaclima greshakei formerly Pseudotropheus greshakei) is a tropical freshwater fish belonging to the Cichlidae family and is one of the most commonly kept ornamental cichlids; the most commonly cultured cichlids are tilapia (Oreochromis spp.), which are important as a food fish species. M. greshakei, often known as mbuna (rock dwelling) cichlids, are endemic to Lake Malawi, East Africa and are used as models of evolutionary speciation because of their diversity ${ }^{(11)}$. In the aquarium trade, many cichlid fish are highly valued and important species, which include discus, angelfish and oscars. In this study, M. greshakei was used as a model ornamental cichlid to establish a range of blood haematology and chemistry parameters, for use as a diagnostic tool.

\section{Materials and methods}

The study was reviewed and approved by the WALTHAM ${ }^{\circledR}$ Ethical Review Committee and complied with Home Office regulations.

\section{Animals and diet}

The first generation of male red top ice blue cichlids bred from parent cichlids was used in this research study (on 31 July 2007 and 11 September 2007), at an age of 28 months. This study included only male fish due to volume requirements for blood sampling. These fish were maintained individually in 50-litre glass aquaria, because of their aggressive behaviour. These aquaria were an integral component of a tropical re-circulating system held at $24 \cdot 8 \pm 0 \cdot 1^{\circ} \mathrm{C}$ with $12: 12 \mathrm{~h}$ photoperiod. Chemical water parameters were maintained at a $\mathrm{pH}$ 
of $7 \cdot 3(\mathrm{se} 0 \cdot 1), 0 \mathrm{mg} / 1$ ammonia, $9 \cdot 2(\mathrm{SE} 5 \cdot 7) \mathrm{mg} / \mathrm{l}$ nitrate and $0 \mathrm{mg} / \mathrm{l}$ nitrite, and were measured using a $\mathrm{HACH} \mathrm{DR} / 2500$ spectrophotometer. The cichlids were fed to satiation with a combination of AQUARIAN ${ }^{\circledR}$ tropical flake and pellets (MARS Fishcare, Chalfont, PA, USA) by automatic feeders, 4-5 times a day. Fish were not fed on the day of sampling.

\section{Blood sampling and analysis}

Blood samples of sixteen cichlids, with a mean weight of $99 \cdot 7$ ( $\operatorname{se} 4 \cdot 1) \mathrm{g}$, were taken on two occasions, 6 weeks apart. On the first occasion eight fish were sampled for plasma chemistry and eight for haematology and this order was reversed on the second occasion. Immediately following capture, individual fish were supported with a foam rubber cradle upside down in a water-filled bowl. The head of the fish was covered with a moist towel, to reduce stress. Blood was withdrawn from the caudal vein using a $1 \mathrm{ml}$ sterile pre-heparinzed syringe with a $22 \mathrm{G} \times 1^{\prime}$ needle and was divided into two lithium heparin tubes. One tube was spun at $4^{\circ} \mathrm{C}, 200 \mathbf{g}$ for $10 \mathrm{~min}$ using a Jouan BR4i centrifuge and the plasma was frozen at $\left(80^{\circ} \mathrm{C}\right.$ until analysis. Plasma was analysed for the following biochemical parameters using an Olympus AU400 Clinical Chemistry Autoanalyzer (Olympus, Tokyo, Japan): protein, albumin, glucose, $\mathrm{P}, \mathrm{Ca}, \mathrm{Na}, \mathrm{K}, \mathrm{Cl}$, alkaline phosphatase, alanine aminotransferase, aspartate aminotransferase, cholesterol, urea and creatinine. Globulins were calculated from the difference between total protein and albumin values. A separate whole-blood sample was drawn into a heparinized capillary tube and the haematocrit level was determined after centrifugation for $5 \mathrm{~min}$ at $12000 \mathrm{~g}$. Hb was measured using the HemoCue blood haemoglobin system. Absolute cell counts and their differentials were calculated by a modified method of Inoue ${ }^{(12)}$ using a FACSCalibur flow cytometer. The mean cell volume, mean cell $\mathrm{Hb}$ and mean cell $\mathrm{Hb}$ concentration were calculated by standard formulae. Blood smears were made using anticoagulated blood and were stained with Wright-Giemsa for cell cytology observations.

Table 1. Plasma chemistry reference intervals for Metriaclima greshakei $(n 15)^{\star}$

\begin{tabular}{|c|c|c|}
\hline Analyte & Reference interval & Median \\
\hline Total protein (g/l) & $34 \cdot 6-46 \cdot 2$ & $39 \cdot 0$ \\
\hline Albumin $(g / l)$ & $8 \cdot 1-10 \cdot 5$ & 9.5 \\
\hline Globulins (g/l) & $25 \cdot 8-37 \cdot 0$ & $29 \cdot 0$ \\
\hline Glucose (mmol/l) & $2 \cdot 1-2 \cdot 7$ & $2 \cdot 4$ \\
\hline $\operatorname{ALT}(\mathrm{U} / \mathrm{I})$ & $34 \cdot 7-236 \cdot 1$ & $59 \cdot 8$ \\
\hline AST (U/I) & $3 \cdot 5-46 \cdot 3$ & $12 \cdot 5$ \\
\hline ALP (U/I) & $30 \cdot 1-61 \cdot 9$ & 44.5 \\
\hline Cholesterol (mmol/l) & $6 \cdot 8-13 \cdot 9$ & $10 \cdot 6$ \\
\hline Creatinine $(\mu \mathrm{mol} / \mathrm{l})$ & $26 \cdot 5-94 \cdot 1$ & $51 \cdot 2$ \\
\hline $\mathrm{Ca}(\mathrm{mmol} / \mathrm{l})$ & $2 \cdot 5-2 \cdot 7$ & 2.6 \\
\hline $\mathrm{Cl}(\mathrm{mmol} / \mathrm{l})$ & $143 \cdot 0-150 \cdot 0$ & $147 \cdot 0$ \\
\hline $\mathrm{P}(\mathrm{mmol} / \mathrm{l})$ & $1 \cdot 3-1 \cdot 6$ & 1.5 \\
\hline $\mathrm{K}(\mathrm{mmol} / \mathrm{l})$ & $2 \cdot 4-3 \cdot 6$ & $3 \cdot 1$ \\
\hline $\mathrm{Na}(\mathrm{mmol} / \mathrm{l})$ & $156 \cdot 3-163 \cdot 4$ & $161 \cdot 0$ \\
\hline
\end{tabular}

ALT, alanine aminotransferase; AST, aspartate aminotransferase; ALP, alkaline phosphatase.

${ }^{*}$ All data are expressed within $95 \%$ reference intervals.

\section{Data analysis}

Data from previous 'in-house' studies using ornamental fish generated sufficiently small values for standard errors, when using a sample size of fifteen fish. Therefore, the number of fish used in this study was considered statistically adequate, and compares favourably with similar studies reported in the literature ${ }^{(1,13-15)}$. Reference intervals were established following the guidelines proposed by the National Committee for Clinical Laboratory Standards ${ }^{(16)}$. Values were ranked, and the highest and lowest $2.5 \%$ values were discarded, no outliers were identified in this data set. The range of the remaining values was the reference interval. A $t$ test was used to statistically compare the groups of eight fish between time points for plasma chemistry and haematology $(P<0.05)$ using Statgraphics Centurion XVI.

\section{Results}

No statistically significant differences were noted between sample periods for any parameters. Results of the plasma chemistry are shown in Table 1 , one sample was lost due to clotting; therefore values for fifteen fish are reported. Haematology results are shown in Table 2. Data obtained for urea have not been included in this data set as they were under the dynamic range of the assay, and therefore deemed unreliable. Identification of specific leucocyte types was difficult because of the low numbers of these cells and the clarity of the images obtained. However, it was possible to identify several small lymphocytes, some with pseudopodia, a potential large monocyte, due to its abundant blue-grey cytoplasm and a round nucleus, and $G_{1}$ (type 1 ) granulocyte due to its irregular, non-lobed nucleus.

\section{Discussion}

There were no statistically significant differences between sampling periods for haematological or plasma chemistry, indicating that the 6-week period between sampling was sufficient for blood volume and parameter recovery. Low circulating plasma urea levels were expected since this teleost fish is ammonotelic. This species of cichlid remains calm when

Table 2. Haematology reference intervals for Metriaclima greshakei $(n 16)^{\star}$

\begin{tabular}{|c|c|c|}
\hline Analyte & Reference interval & Median \\
\hline $\mathrm{Hb}(\mathrm{g} / \mathrm{l})$ & $63 \cdot 0-91 \cdot 3$ & $75 \cdot 0$ \\
\hline Haematocrit (\%) & $21 \cdot 0-29.5$ & $25 \cdot 3$ \\
\hline Erythrocyte $\left(\times 10^{6} / \mu \mathrm{l}\right)$ & $1.7-2.7$ & $2 \cdot 3$ \\
\hline Leucocyte (per $\mu \mathrm{l})$ & $22867 \cdot 0-55213 \cdot 0$ & $33168 \cdot 0$ \\
\hline $\operatorname{MCV}(\mathrm{fl})$ & $95 \cdot 3-132 \cdot 4$ & $113 \cdot 8$ \\
\hline $\mathrm{MCH}(\mathrm{pg})$ & $26 \cdot 9-40 \cdot 3$ & $33 \cdot 6$ \\
\hline $\mathrm{MCHC}(\mathrm{g} / \mathrm{ml})$ & $2 \cdot 7-3 \cdot 2$ & $3 \cdot 0$ \\
\hline Monocytes (per $\mu l)$ & $109 \cdot 0-1663 \cdot 0$ & $399 \cdot 0$ \\
\hline Granulocytes (per $\mu \mathrm{l}$ ) & $302 \cdot 0-2419 \cdot 0$ & $1482 \cdot 0$ \\
\hline Lymphocytes (per $\mu l$ ) & $21159 \cdot 0-52381.0$ & 30955.0 \\
\hline
\end{tabular}


out of water, therefore anaesthetic was not required while sampling, and so excludes any potential anaesthetic effect on blood parameters ${ }^{(17,18)}$. Glucose levels were within normal ranges, when compared with previously published data for cichlids ${ }^{(6,19)}$, indicating that sampling was undertaken in the absence of a stress response. It should be noted that all the fish used in this study were male, particularly as variations in haematological parameters have been noted between sexes of the same species of fish ${ }^{(20,21)}$

$\mathrm{Cl}, \mathrm{Na}, \mathrm{K}$, creatinine, cholesterol and total protein levels were consistent with values obtained for other tropical freshwater fish $^{(1,6,9,22,23)}$. Albumin level was lower and globulin level was higher with median values of 9.5 and $29 \mathrm{~g} / \mathrm{l} v .24$ and $8 \mathrm{~g} / \mathrm{l}$ in goldfish $^{(13)}$, although similar to those for tilapia ${ }^{(6)}$. A fall in serum albumin can indicate liver disease and is associated with a fall in $\mathrm{Ca}^{(24)}$, which was not reflected in this study. Plasma enzymes are known to be variable between fish species $^{(25)}$ and levels in this study are comparable to common carp $^{(15)}$ and tilapia ${ }^{(6)}$ but are low compared with sturgeon ${ }^{(26)}$ and Atlantic salmon ${ }^{(1)}$. When comparing published data, values are often reported as a mix of both plasma and serum, which are not reflective of each other; it has been suggested that plasma values should be used preferentially ${ }^{(27)}$.

Haematology values for $\mathrm{Hb}$, haematocrit, erythrocyte, mean cell volume, mean cell $\mathrm{Hb}$, mean cell $\mathrm{Hb}$ concentration and cytology are in alignment with those for other fish species, including the cultured tilapia ${ }^{(6,22,14)}$. However, values for $\mathrm{P}$, leucocytes and lymphocytes are lower. These differences may be attributable to water quality and low stocking densities, as fish exposed to higher stocking densities are exposed to poorer water quality and higher bacterial loads, which could induce immune stress. Similar discrepancies have been noted for tilapia and striped bass ${ }^{(6,28)}$. In addition to reporting the first set of blood values for M. Greshakei, to our knowledge, this study highlights the similarities between ornamental and cultured cichlids, indicating that previously established data may be utilized for fish belonging to the same family.

Information about the clinical pathology of freshwater tropical fishes is scarce, despite many species having been kept by hobbyists for years. Many factors need to be taken into consideration when comparing reference intervals between fish species, including water quality, stocking density and the sampling methods used, as these can all influence blood indices.

\section{Acknowledgements}

There are no conflicts of interest to disclose. This research received no specific grant from any funding agency in the public, commercial or not-for-profit sectors. Principal investigator, data collection and manuscript prepared by D. L. S. and intellectual input and support from L. G. A.

\section{References}

1. Sandnes K, Lie $\varnothing$, Waagbø R, et al. (1988) Normal ranges of some blood chemistry parameters in adult farmed Atlantic salmon, Salmo salar. J Fish Biol 32, 129-136.
2. Manera M \& Britti D (2006) Assessment of blood chemistry normal ranges in rainbow trout. J Fish Biol 69, 1427-1434.

3. Miller WR III, Hendricks AC \& Cairns J Jr (1983) Normal ranges for diagnostically important haematological and blood chemistry characteristics of rainbow trout (Salmo gairdneri). Can J Fish Aquat Sci 40, 420-425.

4. Svetina A, Matašin Ž, Tofant A, et al. (2002) Haematology and some blood chemical parameters of young carp till the age of three years. Acta Veterinaria Hungarica 50, 459-467.

5. Bentinck-Smith J, Beleau MH, Waterstrat P, et al. (1987) Biochemical reference ranges for commercially reared channel catfish. Prog Fish Cult 49, 108-114.

6. Hrubec TC, Cardinale JL \& Smith SA (2000) Hematology and plasma chemistry reference intervals for cultured tilapia (Oreochromis Hybrid). Vet Clin Pathol 29, 7-12.

7. Groff JM \& Zinkl JG (1999) Hematology and clinical chemistry of cyprinid fish. Common carp and goldfish. Vet Clin North Am Exot Anim Pract 2, 741-776.

8. Tripathi NK, Latimer KS \& Burnley VV (2004) Hematologic reference intervals for koi (Cyprinus carpio), including blood cell morphology, cytochemistry, and ultrastructure. Vet Clin Pathol 33, 74-83.

9. Sakamoto K, Lewbart GA \& Smith TM (2001) Blood chemistry values of juvenile red pacu (Piaractus brachypomus). Vet Clin Pathol 30, 50-52.

10. Innis C, Davis D, Mandelman J, et al. (2010) Hematologic values of captive Acadian redfish (Sebastes fasciatus). J Zoo Wild Med 41, 432-437.

11. Genner MJ \& Turner GF (2005) The mbuna cichlids of Lake Malawi: a model for rapid speciation and adaptive radiation. Fish Fish 6, 1-34.

12. Inoue $\mathrm{T}$ (2002) A new method for fish leukocyte counting and partial differentiation by flow cytometry. Fish Shell Immunol 13, 379-390.

13. Bailey RE (1957) The effect of estradiol on serum calcium, phosphorus and protein of goldfish. J Exp Zool 136, 455-469.

14. Hrubec TC, Smith SA \& Robertson JL (2001) Age-related changes in haematology and plasma chemistry values of hybrid striped bass (Morone chrysops $\times$ Morone saxatilis). Vet Clin Pathol 30, 8-15.

15. Yang JL \& Chen HC (2003) Serum metabolic enzymes activities and hepatocyte ultrastructure of common carp after gallium exposure. Zool Stud 42, 455-461.

16. National Committee for Clinical Laboratory Standards (1992) How to Define, Determine, and Utilize Reference Intervals in the Clinical Laboratory: Proposed Guidelines. Villanova, PA: Document C28-P.

17. Velišek J, Stejskal V, Kouril J, et al. (2009) Comparison of the effects of four anaesthetics on biochemical blood profiles of perch. Aqua Res 40, 354-361.

18. Smit GL \& Hattingh J (1980) Haematological assessment of generally used freshwater fish blood anticoagulants. $J$ Fish Biol 17, 337-341.

19. Terao T \& Ogawa T (1984) On the biochemical components in the blood of the cultured cichlid fish Tilapia nilotica. Sci Rep Hokkaido Fish Hatch 39, 83-88.

20. Summerfelt RC (1967) Measurement of some haematological characteristics of goldfish. Prog Fish Cult 29, 13-20.

21. Gabriel UU, Ezeri GNO \& Opabunmi, OO (2004) Influence of sex, source, health status and acclimation on the haematology of Clarias gariepinus (Burch, 1822). Afr J Biotechnol 3, 463-467.

22. Kori-Siakpere O, Ake JEG \& Idoge E (2005) Haematological characteristics of the African snakehead, Parachanna obscura. Afr J Biotechnol 4, 527-530. 
23. Stoskopf MK (1993) Clinical pathology. In Fish Medicine, pp. 113-132. Philadelphia, PA: WB Saunders.

24. Casillas E, Myers MS, Rhodes LD, et al. (1986) Serum chemistry of diseased English sole, Parophrys vetulus Girard, from polluted areas of Puget Sound, Washington. J Fish Dis 8, 437-449.

25. Luskova V (1997) Annual cycles and normal values of haematological parameters in fishes. Acta Sc Nat Brno 31, 1-70.

26. Shi X, Li D, Zhuang P, et al. (2006) Comparative blood biochemistry of Amur sturgeon, Acipenser schrenckii, and
Chinese sturgeon, Acipenser sinensis. Fish Physiol Biochem 32, 63-66.

27. Hrubec TC \& Smith SA (1999) Differences between plasma and serum samples for the evaluation of blood chemistry values in rainbow trout, channel catfish, hybrid tilapias, and hybrid striped bass. J Aquat Anim Health 11, $166-122$.

28. Hrubec TC, Smith SA, Robertson JL, et al. (1996) Comparison of hematologic reference intervals between culture system and type of hybrid striped bass. Am J Vet Res 57, 618-623. 